\title{
Studies on Monitoring Land and Water Management in Pakistan
}

\author{
Kyoichi OTSUKI ${ }^{*}$, Naruo MUSHIAKE* ${ }^{*}$ \\ (*Arid Land Research Center, Tottori University, 1390, Hamasaka, Tottori 680, Japan) \\ (**The Japanese Institute of Irrigation and Drainage, Minato-ku, Tokyo 105, Japan)
}

\begin{abstract}
The purpose of this study is to monitor land and water management using remote sensing and Geographical Information System (GIS). The Fourth Drainage Project, which is located in the center of Punjab Province of Pakistan, was selected as a research field. The Project was launched in 1983 to combat the twin menace of waterlogging and salinity; the depth of the water table in $77 \%$ of the area was $0-1.5 \mathrm{~m}$, and $43 \%$ of the land was saline. A newly introduced subsurface drainage system and a remodeled surface drainage system by the project have gradually reduced the waterlogging problem. The salinity problem, however, still remains. Analyzing Landsat-TM, GIS and ground truth data, following results were obtained.

Waterlogging and salinity problems are mainly distributed along the drainage canals. The main reason is that the water table along the drainage canals is shallower due to the relatively low location. The Normalized Difference Vegetation Index (NDVI) tends to be lower along drainage canals and higher along the irrigation canals. It is mainly because of the unbalance of water distribution as a result of the locational disadvantage of downstream farmers. By contrast, an enterprise farm near the project does not show these locational unbalances but exhibits high $N D V I$ values almost all over the farm, except for fallow. It is due to the fact that the water management there is demand-oriented, thus more flexible, and sufficient water is supplied.
\end{abstract}

Key words : Remote sensing, GIS, Waterlogging, Salinity, Pakistan

\section{Introduction}

Population pressure has forced humans to develop agriculture in semiarid and arid lands, which are less suitable for agriculture and very sensitive to environmental changes. Irrigation systems have been introduced to overcome water shortages in these areas since ancient times. Owing to irrigation, the farmers have obtained stable production, but they have been struggling against waterlogging and salinity at the same time. As the scale of the irrigation system has been magnified, waterlogging and salinity problems have been enlarged and have induced a global environmental problem, desertification. The background and mechanisms causing waterlogging and salinity are, however, diverse. It is, therefore, important to monitor land and water management and find the clue to the problems in each case. In this paper, monitoring land and water management in the Indus river basin using remote sensing satellite images and Geographical Information System (GIS) were studied. 


\section{Research field (WAPDA, 1990)}

The Fourth Drainage Project (4DP) area, which is located in the center of Punjab Province of Pakistan, was selected as a research field (see Fig.1). The 4DP consists of Schedule-1 (about $70,000 \mathrm{ha}$ ) and Schedule-2 (about 73,000ha). It was estimated that $77 \%$ of the area suffered from high ground water tables (see Table 1), and $43 \%$ of the area was affected by salinity (see Table2) in the early 1980s. The 4DP, where a subsurface drainage system was newly installed and the surface drainage system was remodeled, was launched in 1983 to combat the twin menace of waterlogging and salinity.

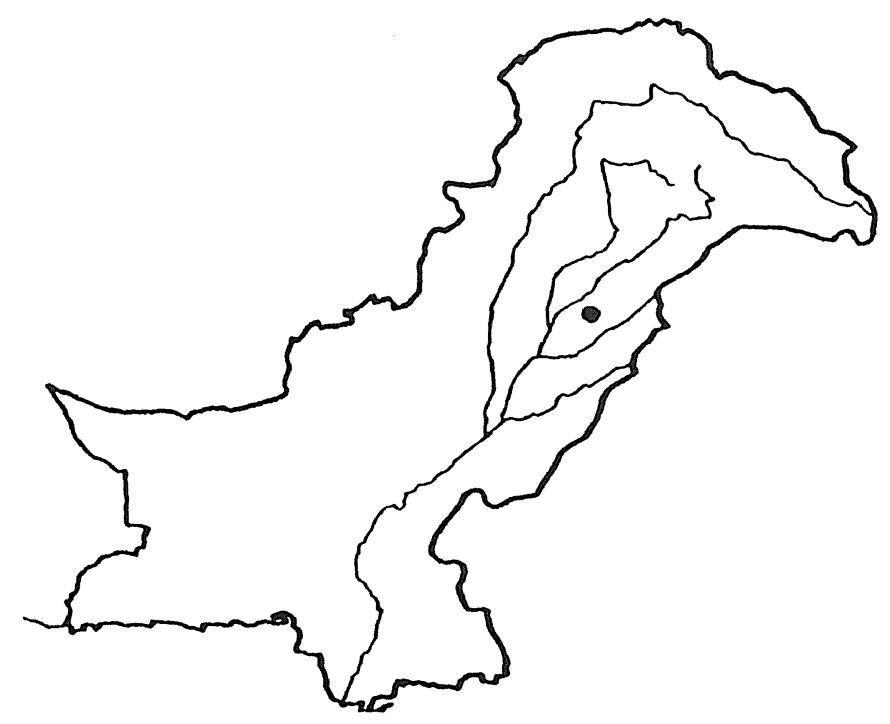

Fig.1 Location of 4DP in Pakistan

Table 1 Waterlogging situation in the 4DP in Jan., 1983

\begin{tabular}{cccc}
\hline Water Table & $0-1.5 \mathrm{~m}$ & $1.5-3.0 \mathrm{~m}$ & below $3.0 \mathrm{~m}$ \\
\hline Area (\%) & $77 \%$ & $21 \%$ & $2 \%$ \\
\hline
\end{tabular}

Table 2 Salinity situation in the 4DP in Jan., 1983

\begin{tabular}{cccc}
\hline Status & Salt free & Saline/Sodic & Saline/Non sodic \\
\hline Area $(\%)$ & $57 \%$ & $35 \%$ & $8 \%$ \\
\hline
\end{tabular}

\section{Method}

3.1 GIS Data related to irrigation, drainage, geography, agriculture, etc. have been collected and input for GIS. Ground truths were conducted twice in January and September, 1995.

3.2 Remote sensing Landsat TM data (Jan. 26 \& Aug. 22, 1993) were used for analysis. The Normalized Differential Vegetation Index (NDVI) was calculated as the index of vegetation
density using the following equation.

$$
N D V I=(\text { Band } 4-\text { Band } 3) /(\text { Band } 4+\text { Band } 3)
$$




\section{Results and discussion}

4.1 Water balance Annual precipitation is small (about $300 \mathrm{~mm}$ ) but largely fluctuate from $73 \mathrm{~mm} / \mathrm{y}$ to $358 \mathrm{~mm} / \mathrm{y}$ during $1986-1993$. In this range, Net Primary Productivity (NPP) of natural vegetation was too small and too sensitive to changes in precipitation (see Fig.2). As NPP is closely related to agricultural productivity in rainfed farming, it is certain that irrigation is necessary to obtain stable agriculture in this area. However, the design water allocation from the canal irrigation system is very small $(1.8-2.1 \mathrm{~mm} / \mathrm{d})$. It is only half of average crop water requirement. Ground water, which used to be widely utilized as supplemental irrigation water, has become too saline to irrigate. Thus, the available irrigation water for crops in the field is only $0.9 \mathrm{~mm} / \mathrm{d}$, considering the average water delivery loss (40\%) and field irrigation loss (25\%). From these data, it is evident that water shortage is one of the fundamental problems in the 4DP.

Although the irrigation water supply for the field is not sufficient, seepage losses from the widely spread webs of the irrigation canal system has enhanced the water table from $20 \mathrm{~m}$ in 1920 to $1.5 \mathrm{~m}$ in 1980 . It is the other major problem in the 4DP.

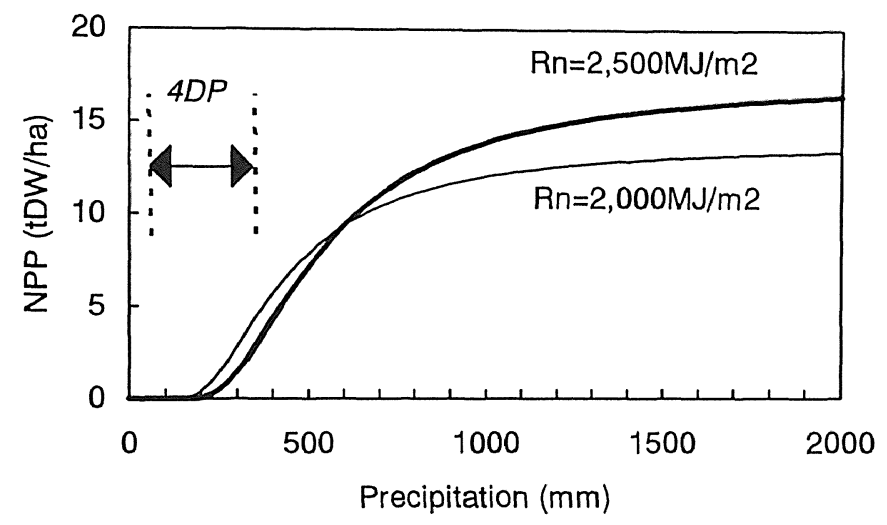

Fig.2 Relation between NPP and precipitation

4.2 Water logging and salinity In the 4DP, the irrigation canals are set on relatively high locations and the drainage canals are situated on rather low locations to utilize the natural gradients effectively. Thus the water table along the drainage canals tends to be shallower than the one along the irrigation canals. The TM/GIS composite pictures show that waterlogging and salinity are mainly located along the drainage canals. A similar result was reported in Mexico by Casas (1995).

According to the TM data and the questionnaire to 90 farmers, waterlogging has reduced (96\% answered that drainage has been improved by the 4DP), whereas the water shortage has remained ( $98 \%$ complained of a water shortage). Most farmers complain that the salinity problem has not yet been resolved because of the water shortage.

4.3 Agricultural productivity Fig. 3 and Table 3 show NDVI along the irrigation and drainage canals. It shows that the vegetation is rather scarce as a whole and the vegetation along the irrigation canals is thriving more than that along the drainage canals. An enterprise farm near the 4DP, in which water was allocated at about three times more than the average of the 4DP (by way of meeting the demand), also shows conspicuously high NDVI. These data show the possibility of resolving the remaining salinity problem. 


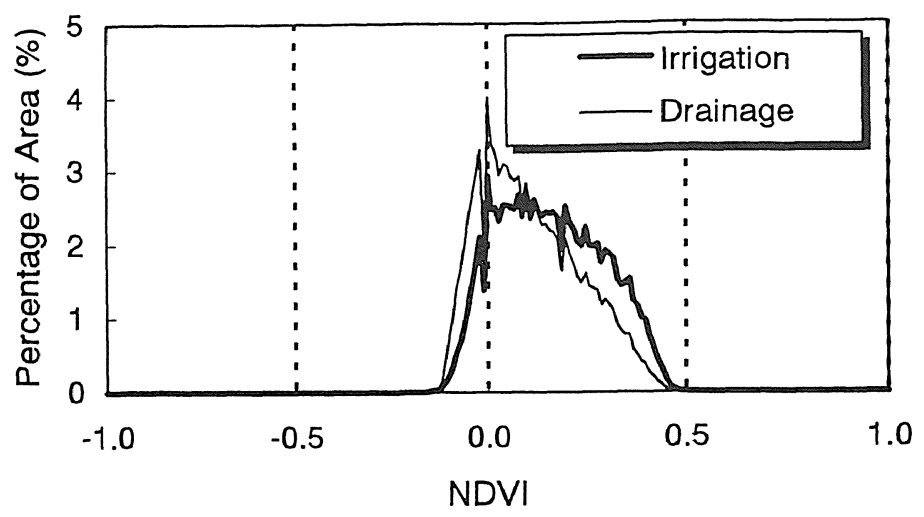

Fig.2 NDVI within $1 \mathrm{~km}$ corridors along the irrigation \& drainage canals

Table 3 Average NDVI in the 4DP

\begin{tabular}{ccc}
\hline \multirow{2}{*}{ Location } & \multicolumn{2}{c}{ NDVI } \\
\cline { 2 - 3 } & $\mathrm{Jan} .26,1993$ & Aug.22, 1993 \\
\hline Along the irrigation canals $(1 \mathrm{~km})$ & 0.154 & 0.158 \\
Along the drainage canals $(1 \mathrm{~km})$ & 0.113 & $0.107,-13$ \\
- Whole area & 0.139 & 0.141 \\
\hline
\end{tabular}

\section{Conclusion}

The newly introduced subsurface drainage system and the remodeled surface drainage system by the 4DP have gradually reduced the waterlogging problem, whereas the salinity problem still remains. The farmers along the drainage canals suffer from the twin menace of waterlogging and salinity. Waterlogging and salinity occur there because the drainage canals are situated on rather low land, which leads to the water tables becoming relatively high. Moreover, the water supply near the drainage canal tends to be less than the design allocation, which is itself poor, because drainage canals are located at the end of irrigation canals. Therefore, vegetation along the drainage canals is more sparse than that along the irrigation canals. By contrast, an enterprise farm near the $4 \mathrm{DP}$ exhibits high $N D V I$ values almost all over the farm, except for fallow. It is attributed to the fact that the water management is demand-oriented, thus more flexible, and sufficient water is supplied.

Acknowledgments The authors thank all the colleges of a joint Pakistani-Japanese research group (mainly Water and Power Development Authority and the Japanese Institute of Irrigation and Drainage Mission) and Punjab Irrigation and Power Department.

\section{References}

Casas, S., 1995 : Salinity assessment based on combined use of remote sensing and GIS, Use of Remote Sensing Techniques in Irrigation and Drainage, pp.141-150, FAO, Rome, Italy

WAPDA, 1990 : Project report Fourth Drainage Project, IWASRI, Lahore, Pakistan

WAPDA, 1994 : Monitoring and evaluation Fourth Drainage Project, WAPDA, Lahore, Pakistan 